\title{
Inhaled prostacyclin is safe, effective, and affordable in patients with pulmonary hypertension, right heart dysfunction, and refractory hypoxemia after cardiothoracic surgery
}

\author{
Charl J. De Wet, MBChB ${ }^{a, b}$ \\ David G. Affleck, MD ${ }^{\mathrm{b}}$ \\ Eric Jacobsohn, MBChB, MHPE, FRCPC ${ }^{a, b}$ \\ Michael S. Avidan, MBBCh ${ }^{a, b}$ \\ Heidi Tymkew, MHS ${ }^{a, b}$ \\ Laureen L. Hill, MD ${ }^{a, b}$ \\ Paul B. Zanaboni, MD, PhD \\ Nader Moazami, MD \\ Jennifer R. Smith, PharmD ${ }^{c}$
}

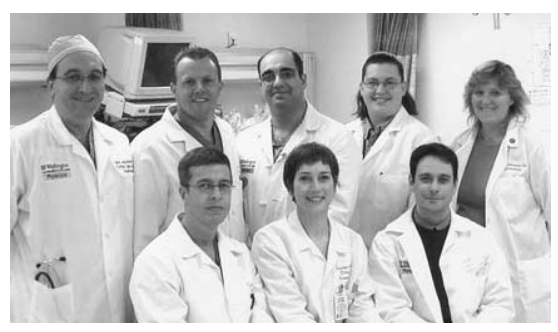

Jacobsohn, Affleck, Moazami, Smith, and Tymkew (standing, left to right). De Wet, Hill, and Avidan (sitting, left to right).
From the Department of Anesthesiology ${ }^{\mathrm{a}}$ and Division of Cardiothoracic Surgery, ${ }^{b}$ Washington University School of Medicine and Barnes Jewish Hospital, St Louis, Mo, and Department of Pharmacy, ${ }^{\mathrm{c}}$ Barnes Jewish Hospital, St Louis, Mo.

Funding was provided by a grant from the Barnes Jewish Hospital Foundation.

Presented at the Society of Cardiovascular Anesthesiology Meeting, Miami, Fla, May 2003, and the Twenty-ninth Annual Meeting of The Western Thoracic Surgical Association, Carlsbad, Calif, June 18-21, 2003.

Received for publication June 17, 2003; revisions requested Sept 11, 2003; revisions received Nov 5, 2003; accepted for publication Dec 1, 2003.

Address for reprints: Eric Jacobsohn, MBChB, MHPE, FRCPC, Washington University School of Medicine, Department of Anesthesiology, 660 Euclid Ave, Campus Box 8054, St Louis, MO 63110 (Email: jacobsoe@msnotes.wustl.edu).

J Thorac Cardiovasc Surg 2004;127:1058-67

$0022-5223 / \$ 30.00$

Copyright () 2004 by The American Association for Thoracic Surgery

doi:10.1016/j.jtcvs.2003.11.035
Background: The purpose of this study was to describe our institutional experience in using inhaled prostacyclin as a selective pulmonary vasodilator in patients with pulmonary hypertension, refractory hypoxemia, and right heart dysfunction after cardiothoracic surgery.

Methods: Between February 2001 and March 2003, cardiothoracic surgical patients with pulmonary hypertension (mean pulmonary artery pressure $>30 \mathrm{~mm} \mathrm{Hg}$ or systolic pulmonary artery pressure $>40 \mathrm{~mm} \mathrm{Hg})$, hypoxemia $\left(\mathrm{PaO}_{2} /\right.$ fraction of inspired oxygen $<150 \mathrm{~mm} \mathrm{Hg}$ ), or right heart dysfunction (central venous pressure $>16 \mathrm{~mm} \mathrm{Hg}$ and cardiac index $<2.2 \mathrm{~L} \cdot \min ^{-1} \cdot \mathrm{m}^{-2}$ ) were prospectively administered inhaled prostacyclin at an initial concentration of $20,000 \mathrm{ng} / \mathrm{mL}$ and then weaned per protocol. Hemodynamic variables were measured before the initiation of inhaled prostacyclin, 30 to 60 minutes after initiation, and again 4 to 6 hours later.

Results: One hundred twenty-six patients were enrolled during the study period. At both time points, inhaled prostacyclin significantly decreased the mean pulmonary artery pressure without altering the mean arterial pressure. The average length of time on inhaled prostacyclin was 45.6 hours. There were no adverse events attributable to inhaled prostacyclin. The average cost for inhaled prostacyclin was $\$ 150$ per day. Compared with nitric oxide, which costs $\$ 3000$ per day, the potential cost savings over this period were $\$ 681,686$.

Conclusions: Inhaled prostacyclin seems to be a safe and effective pulmonary vasodilator for cardiothoracic surgical patients with pulmonary hypertension, refractory hypoxemia, or right heart dysfunction. Overall, inhaled prostacyclin significantly decreases mean pulmonary artery pressures without altering the mean arterial pressure. Compared with nitric oxide, there is no special equipment required for administration or toxicity monitoring, and the cost savings are substantial.

Because of a potential conflict of interest related to this manuscript on the part of our editors, Dr David A. Fullerton served as guest section editor, assigned reviewers, and made editorial decisions or recommendations leading to its acceptance for publication. 


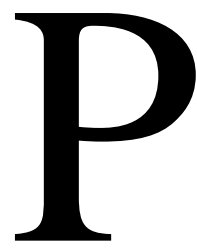

ulmonary hypertension, right ventricular dysfunction, and perioperative hypoxemia are common problems that necessitate treatment in a cardiothoracic intensive care unit. Inhaled nitric oxide (iNO) was the first agent shown to be a selective pulmonary artery vasodilator, and it has also been shown to improve oxygenation in patients with acute lung injury and adult respiratory distress syndrome (ARDS) ${ }^{1,2}$ Nitric oxide, however, has become prohibitively expensive and has several associated toxicities that necessitate monitoring, which further increases the cost. $^{3}$

In the search for a selective pulmonary artery vasodilator, both as an alternative and possibly as a complement to iNO, several drugs administered via the inhalational route have been described in animal models and humans. These include inhaled sodium nitroprusside, nitroglycerin, class 5 phosphodiesterase inhibitors (such as zaprinast and sildenafil), milrinone, prostaglandin $\mathrm{E}_{1}\left(\mathrm{PGE}_{1}\right.$; alprostadil), $\mathrm{PGI}_{2}$ (prostacyclin), and iloprost (the stable analog of $\left.\mathrm{PGI}_{2}\right){ }^{4}$ The use of intravenous $\mathrm{PGI}_{2}$ was first described in 1978 in canine experiments. ${ }^{5}$ As opposed to $\mathrm{PGE}_{1}, \mathrm{PGI}_{2}$ was shown not to have any pulmonary inactivation and was therefore 10 times more potent than a systemic vasodilator, even though its metabolite 6-keto-prostaglandin $\mathrm{F}_{1} \alpha$ had few systemic vasodilator properties. However, intravenous $\mathrm{PGI}_{2}$, as opposed to intravenous $\mathrm{PGE}_{1}$, became an important pulmonary vasodilator in the treatment of pulmonary hypertension. ${ }^{6}$ However, in some patients with pulmonary hypertension, the intravenous doses required to decrease pulmonary artery pressures (PAPs) are often so high that significant systemic hypotension occurs. In 1993, Welte and colleagues ${ }^{7}$ reported that inhaled $\mathrm{PGI}_{2}\left(\mathrm{iPGI}_{2}\right)$ resulted in selective pulmonary artery vasodilation in dogs. It has been shown to be as effective as iNO in reducing pulmonary vascular resistance in heart transplant candidates, ${ }^{8}, 9$ in decreasing PAPs in primary and secondary pulmonary hypertension, ${ }^{10}$ and in improving right ventricular function in animals with hypoxic pulmonary vasoconstriction ${ }^{11}$; it is also effective as a selective pulmonary artery vasodilator, with improvement in oxygenation in patients with ARDS. ${ }^{12-14}$ Compared with iNO, it is less expensive, is easier to administer, is relatively free of side effects, and requires no special toxicity monitoring.

The manufacturer has not sought Food and Drug Administration (FDA) approval for inhalational administration of $\mathrm{PGI}_{2}$. The objective of this case series was to report our institutional experience with $\mathrm{iPGI}_{2}$ in critically ill cardiothoracic surgical patients. Our secondary aim was to determine whether it is easy to use during surgery as well as in the intensive care setting and to perform a cost analysis comparing it with iNO.

\section{Methods}

The Human Studies Committee at Washington University Medical School approved the study, and all enrolled patients signed written, informed consent. Before initiation of the study, the principal investigator (E.J.) obtained an investigational new drug application from the FDA. This was done so we could investigate a new route of administration of a previously approved drug.

One hundred twenty-six patients (67 men and 59 women with a mean age of $56 \pm 15$ years) were enrolled in this prospective, interventional study of $\mathrm{iPGI}_{2}$. The inclusion criteria were cardiothoracic surgery patients with pulmonary hypertension, right ventricular dysfunction, or refractory hypoxemia in the perioperative period. Pulmonary hypertension was defined as a mean PAP (MPAP) $30 \mathrm{~mm} \mathrm{Hg}$ or more or systolic PAP $40 \mathrm{~mm} \mathrm{Hg}$ or more. Right ventricular failure was defined as a central venous pressure (CVP) $16 \mathrm{~mm} \mathrm{Hg}$ or more and cardiac index less than $2.2 \mathrm{~L}$. $\min ^{-1} \cdot \mathrm{m}^{-2}$. Refractory hypoxemia was defined as a ratio of arterial partial oxygen pressure to fraction of inspired oxygen $\left(\mathrm{PaO}_{2} / \mathrm{FIO}_{2}\right.$ ratio) less than $150 \mathrm{~mm} \mathrm{Hg}$. Clinicians first attempted to improve oxygenation by conventional methods. These included strategies such as: 1) increasing the inspired oxygen tension, 2) optimizing functional residual capacity with the best positive endexpiratory pressure (PEEP) and recruitment maneuvers, 3) optimizing the inspiration-expiration ratio, 4) selecting the most appropriate mode of mechanical ventilation, and 5) using neuromuscular blockade when indicated. The exclusion criteria were patients younger than 18 years of age, pregnant patients, and those with a known allergy or sensitivity to $\mathrm{PGI}_{2}$ or the diluent (glycine). Hemodynamic variables were measured before the initiation of $\mathrm{iPGI}_{2}, 30$ to 60 minutes after the initiation, and every 6 hours thereafter. The study was designed to optimize patient safety and ease of use while maintaining clinician autonomy. Clinicians were free to titrate inotropes, vasoconstrictors, or vasodilators to maintain mean arterial blood pressure (MAP), cardiac output, or both. Side effects attributable to the use of $\mathrm{PPGI}_{2}$ were recorded. All adverse events were reported to the Human Studies Committee and then reviewed by a data safety monitoring committee for a further in-depth review.

$\mathrm{PGI}_{2}$ is supplied as a sodium salt of epoprostenol (Flolan; Glaxo Wellcome Inc, Research Triangle Park, NC). It is reconstituted in $50 \mathrm{~mL}$ of glycine buffer diluent (sterile diluent for Flolan) to a final concentration of $20,000 \mathrm{ng} / \mathrm{mL}$. It is then nebulized by using a continuous nebulizer system (MiniHEART nebulizer; Westmed, Tucson, Ariz). This is attached to the inspiratory limb of the ventilator circuit or via face mask with a Venturi attachment for aerosolization. For continuous administration, a $60-\mathrm{mL}$ syringe of $\mathrm{PGI}_{2}(20,000 \mathrm{ng} / \mathrm{mL})$ is attached to a standard intravenous pump and delivered at a constant rate of $8 \mathrm{~mL} / \mathrm{h}$ to the nebulizer chamber. The nebulizer chamber is primed with $15 \mathrm{~mL}$ of the $\mathrm{PGI}_{2}$ solution, and at a nebulizing oxygen flow rate of 2 to $3 \mathrm{~L} / \mathrm{min}$, approximately $8 \mathrm{~mL} / \mathrm{h}$ is nebulized. The glycine buffer diluent is "sticky," and we therefore decided to empirically change filters on the ventilator every 2 hours to prevent ventilator valve malfunction. To support continuous nebulization, a heated wire circuit was added to the ventilator. The $\mathrm{PGG}_{2}$ concentration was weaned by $50 \%$ every 2 to 4 hours until a concentration of $2500 \mathrm{ng} / \mathrm{mL}$ was reached (20,000 to 10,000 to 5000 to $2500 \mathrm{ng} / \mathrm{mL})$, as long as the patient did not have a negative response. A negative response was 

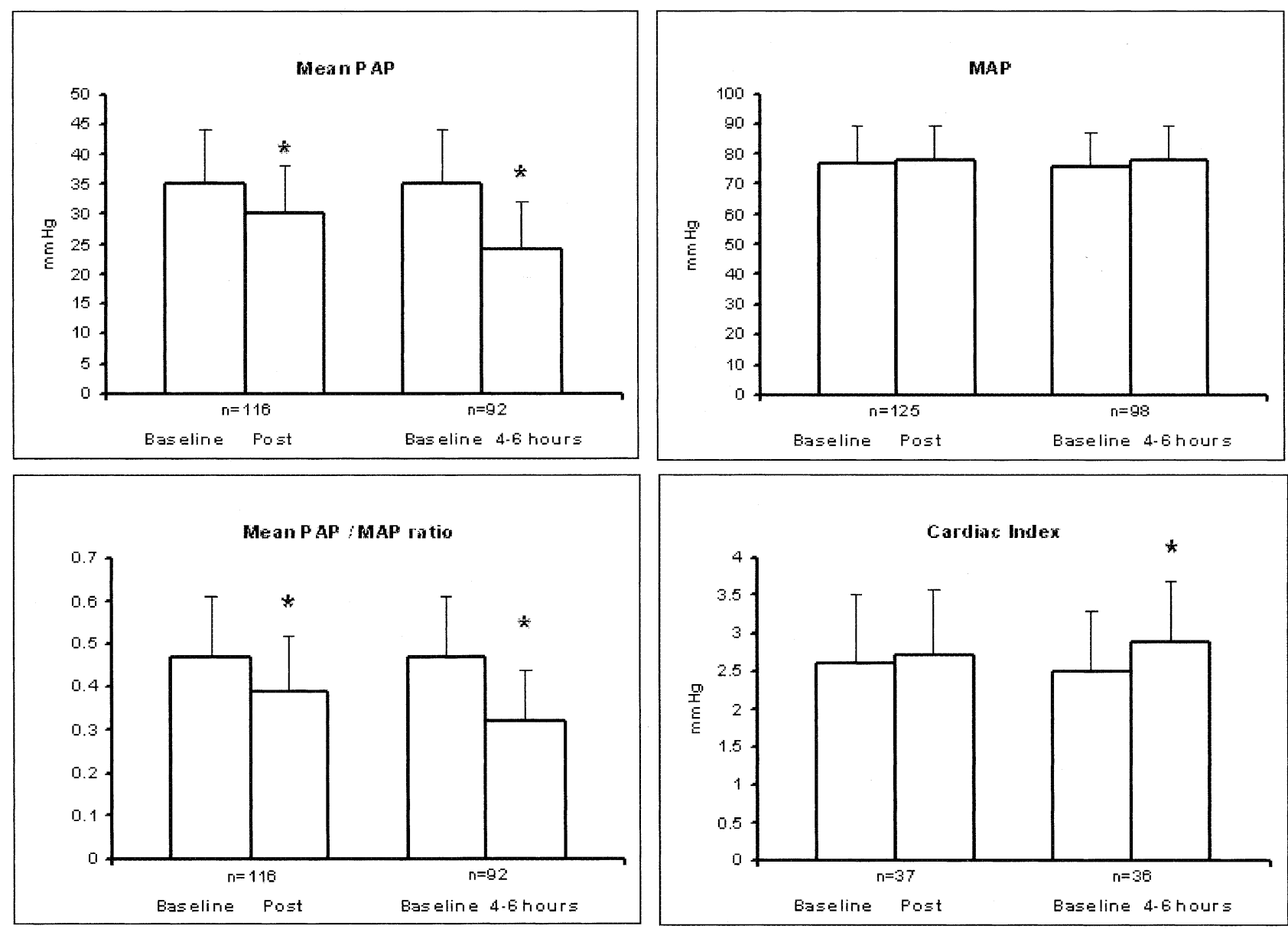

Figure 1. Effect of $\mathrm{iPGI}_{2}$ on MPAP, MAP, the MPAP/MAP ratio, and cardiac index for all patients: $P<.001$. The smaller number of patients at the 4- to 6-hour time periods are compared with their own baseline. The numbers at this time period are smaller because some of the original patients were no longer receiving $\mathrm{iPGI}_{2}$ or had incomplete data.

defined as an increase in PAP by $15 \%$ or a decline in cardiac index or the $\mathrm{PaO}_{2} / \mathrm{FIO}_{2}$ ratio by $10 \%$. Systemic arterial pressure was closely monitored, and the $\mathrm{PGI}_{2}$ dose was adjusted accordingly if a clinical change in blood pressure was observed.

The major aim of this study was to evaluate the immediate and sustained effects of $\mathrm{iPGI}_{2}$ on PAPs in patients with pulmonary hypertension, right ventricular dysfunction, and refractory hypoxemia. Previous studies have shown reductions in MPAP of at least $8 \mathrm{~mm} \mathrm{Hg}$ (SD, $7.5 \mathrm{~mm} \mathrm{Hg}$ ) with iPGI $_{2}$. On the basis of these findings, 9 patients would be required to demonstrate a mean decrease in PAP of $8 \mathrm{~mm} \mathrm{Hg}(\mathrm{SD}, 8 \mathrm{~mm} \mathrm{Hg}$ ) with a power of $90 \%$ and a $P$ value of .05 . With the large number of patients we were planning to recruit $(>100)$, the study was adequately powered to detect effects of $\mathrm{PPGI}_{2}$ on PAP in each subgroup.

The Shapiro-Wilke test of normality was used to assess the distribution of the continuous data. Variables were normally distributed. Paired Student $t$ tests were used to evaluate the changes seen in hemodynamic and oxygenation parameters. The SPSS statistical package (SPSS, Chicago, Ill) was used for all analyses.
A post hoc analysis of patients with refractory hypoxemia was performed.

\section{Results}

One hundred twenty-six patients were prospectively enrolled during the study period. The demographics are shown in Table 1. The average time on $\mathrm{iPGI}_{2}$ was 45.6 hours (range, 0.1-390 hours). Tables 2 through 7 show the analysis for the 3 groups of patients that were enrolled. At both time points (after initiation and at 4-6 hours), iPGI 2 significantly decreased the MPAP. The ratio of MPAP to MAP improved significantly at both time points. Further, no significant changes were observed in MAP at the same time points, demonstrating the selective pulmonary effects of $\mathrm{iPGI}_{2}$. The effect of $\mathrm{iPGI}_{2}$ on all hemodynamic parameters is reported in Tables 8 and 9. Although the entire group did not show an improvement in the $\mathrm{PaO}_{2} / \mathrm{FIO}_{2}$ ratio, post hoc analysis 
showed that in patients with refractory hypoxemia, there was a significant improvement in the $\mathrm{PaO}_{2} / \mathrm{FIO}_{2}$ ratio (Tables 2 and 3). The initial $\mathrm{PaO}_{2} / \mathrm{FIO}_{2}$ increased from $85 \pm 33$ to $158 \pm 114(P=.001)$. For those patients with refractory hypoxemia who remained on the treatment at 4 to 6 hours, the $\mathrm{PaO}_{2} / \mathrm{FIO}_{2}$ ratio increased from $95 \pm 36$ to $186 \pm 111$ $(P=.001)$.

There was a substantial cost savings compared with iNO. The total cost for administering $\mathrm{iPGI}_{2}$ is approximately $\$ 150$ per day. The cost for iNO is $\$ 125$ per hour, or $\$ 3000$ per day. Total patient hours of $\mathrm{PPGI}_{2}$ administration were 5740.50 hours. The total $\mathrm{iPGI}_{2}$ cost was $\$ 35,878$, versus a calculated nitric oxide cost of $\$ 717,564$. This amounts to a calculated cost savings of $\$ 681,686$.

There were few adverse events attributable to $\mathrm{iPGI}_{2}$. No patients complained of facial flushing. There was no significant systemic hypotension. There were no clinically significant bleeding events. Within 30 days, there were 2 reexplorations for postoperative bleeding $(2 / 126 ; 1.6 \%), 6$ cases of renal failure $(6 / 126 ; 1.6 \%)$, and 1 new stroke $(1 / 126 ; 0.8 \%)$. There were 2 perioperative cardiac arrests $(2 / 126 ; 1.6 \%)$. There was 1 serious adverse event related to the use of the "sticky" glycine diluent. An exhalation valve on a ventilator became stuck, and this resulted in significant auto-PEEP and hypotension. The problem was diagnosed early, and there were no sequelae. On several patients, the mainstream end-tidal $\mathrm{CO}_{2}$ analyzers ceased to function because of excess moisture accumulation. The overall 30-day mortality rate was $12.7 \%$.

\section{Discussion}

Inhaled aerosolized $\mathrm{PGI}_{2}$ has been described in a number of small human studies for use in patients with ARDS, ${ }^{12-15}$ primary and secondary pulmonary hypertension, ${ }^{10,16}$ and right ventricular failure or dysfunction ${ }^{9,17}$ and to improve oxygenation. ${ }^{18,19}$ It has also been shown to be as effective as iNO. ${ }^{8,12,13,20-22}$ However, centers that use iPGI $_{2}$ use it via a non-FDA-approved route of administration. Similarly, iNO used for indications other than pulmonary hypertension is used for a non-FDA-approved indication. After obtaining a FDA investigational new drug application, we set out to document and demonstrate its efficacy, safety, ease of administration, and cost in a large cardiothoracic surgical operating room and intensive care unit. We found that $\mathrm{iPGI}_{2}$ was effective as a selective pulmonary artery vasodilator in patients with pulmonary hypertension and right ventricular dysfunction, and improved oxygenation in patients with refractory hypoxemia. It acutely decreased PAPs while MAP was maintained. This resulted in an improvement in the MPAP/MAP ratio. Inhaled $\mathrm{PGI}_{2}$ was also effective in improving oxygenation regardless of the etiology of hypoxemia. In patients with poor oxygenation, $\mathrm{iPGI}_{2}$ not only improved oxygenation, but was also effective as a pulmonary vasodilator while maintaining MAP and cardiac out-
TABLE 1. Demographics $(n=126)$

\begin{tabular}{lr}
\hline Variable & Data \\
\hline Age (y) (mean \pm SD) & $56 \pm 15$ \\
Weight, (kg) (mean \pm SD) & $77 \pm 22$ \\
Sex & \\
Male & 67 \\
Female & 59 \\
Cardiac operation & 78 \\
CABG & 17 \\
CABG + valve & 11 \\
Valve & 17 \\
Heart transplantation & 12 \\
LVAD & 15 \\
Other* & 6 \\
Lung transplantation & 43 \\
Thoracic operation & 5 \\
Enrollment criteria† & \\
Pulmonary hypertension & 110 \\
RV dysfunction & 14 \\
Refractory hypoxemia & 32
\end{tabular}

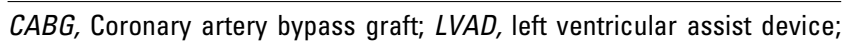
$R V$, right ventricular.

*Other cardiac operations included atrial septal defect repair, maze-atrial septal defect, pulmonary thromboendarterectomy, post-extracorporeal membrane oxygenator removal after redo-aortic valve replacement, thoracoabdominal aortic aneurysm repair, post-chest wound re-exploration. tNote that some patients met more than 1 of the 3 inclusion criteria.

put. Our study also demonstrates that there did not seem to be any appreciable tolerance to any of the beneficial effects after 4 to 6 hours of administration.

Inhaled $\mathrm{PGI}_{2}$ binds to subunits of the prostaglandin $\mathrm{G} /$ protein receptor, which results in an increase in cyclic adenosine monophosphate, ${ }^{23}$ as opposed to iNO, which results in an increase in cyclic guanosine monophosphate. ${ }^{3}$ Many of iNO's associated toxicities are thought to be related to the increase in cyclic guanosine monophosphate that interferes with normal cellular proliferation, including DNA strand breaks and potential mutagenic base alterations. ${ }^{3} \mathrm{PGI}_{2}$ has a short half-life of 5 minutes. It is rapidly hydrolyzed at acid or physiologic pH to 6-keto-prostaglandin $\mathrm{F}_{1} \alpha,{ }^{24,25}$ which has been shown to have few vasodilator properties. ${ }^{5}$ As opposed to $\mathrm{PGE}_{1}$ (alprostadil), which is commonly used to prevent reperfusion injury or as an intravenous pulmonary artery vasodilator in the perioperative period, intravenous $\mathrm{PGI}_{2}$ is not inactivated in the pulmonary circulation. Because of this lack of pulmonary inactivation, $\mathrm{PGI}_{2}$ is 10 times more potent as a systemic vasodilator than $\mathrm{PGE}_{1}{ }^{5}$

As with iNO, there are theoretical concerns regarding the potential antiplatelet effects of $\mathrm{PGI}_{2}$ and its metabolite 6-keto-prostaglandin $\mathrm{F}_{1} \alpha{ }^{24,26}$ Platelet/endothelial cell adhesion is regulated by endothelial cell-derived mediators, including $\mathrm{PGI}_{2}$ and endothelium-derived relaxing factor. $\mathrm{PGI}_{2}$ 
TABLE 2. Hemodynamic parameters for patients with refractory hypoxemia: baseline and after $\mathrm{iPGI}_{2}$

\begin{tabular}{|c|c|c|c|c|}
\hline Variable & Before $\mathrm{iPGI}_{2}$ & After $\mathrm{iPGI}_{2}$ & $\mathbf{n}$ & $P$ value \\
\hline $\mathrm{PaO}_{2} / \mathrm{FlO}_{2}$ ratio & $85 \pm 33$ & $158 \pm 114$ & 27 & .001 \\
\hline $\mathrm{MAP}(\mathrm{mm} \mathrm{Hg})$ & $77 \pm 11$ & $75 \pm 10$ & 32 & .331 \\
\hline $\mathrm{PAP}(\mathrm{mm} \mathrm{Hg})$ & $32 \pm 9$ & $28 \pm 9$ & 26 & .014 \\
\hline MPAP/MAP ratio & $0.43 \pm 0.13$ & $0.35 \pm 0.20$ & 26 & .039 \\
\hline $\mathrm{Cl}\left(\mathrm{L} \cdot \mathrm{min}^{-1} \cdot \mathrm{m}^{-2}\right)$ & $2.7 \pm 1.1$ & $2.6 \pm 0.7$ & 13 & .504 \\
\hline CVP $(\mathrm{mm} \mathrm{Hg})$ & $17 \pm 6$ & $17 \pm 7$ & 24 & .358 \\
\hline Wedge $(\mathrm{mm} \mathrm{Hg})$ & $21 \pm 4$ & $17 \pm 2$ & 2 & .5 \\
\hline PVR (dynes $\cdot \mathrm{s} \cdot \mathrm{cm}^{-5}$ ) & $191 \pm 47$ & $179 \pm 146$ & 2 & .892 \\
\hline SVR (dynes $\cdot \mathrm{s} \cdot \mathrm{cm}^{-5}$ ) & $1315 \pm 655$ & $1163 \pm 364$ & 8 & .297 \\
\hline
\end{tabular}

${ }_{i P G I}$, Inhaled prostacyclin; $M A P$, mean arterial blood pressure; $P A P$, pulmonary artery pressure; $M P A P$, mean pulmonary artery pressure; $C l$, cardiac index; $C V P$, central venous pressure; $P V R$, pulmonary vascular resistance; $S V R$, systemic vascular resistance.

TABLE 3. Hemodynamic parameters for patients with refractory hypoxemia: baseline and after 4 to $6 \mathrm{~h}$ on $\mathrm{iPGI}_{2}$

\begin{tabular}{|c|c|c|c|c|}
\hline Variable & Before $\mathrm{iPGI}_{2}$ & 4 to $6 \mathrm{~h}$ after & $n$ & $P$ value \\
\hline $\mathrm{PaO}_{2} / \mathrm{FlO}_{2}$ ratio & $95 \pm 36$ & $186 \pm 111$ & 17 & .001 \\
\hline $\mathrm{MAP}(\mathrm{mm} \mathrm{Hg})$ & $76 \pm 11$ & $78 \pm 12$ & 25 & .465 \\
\hline PAP (mm Hg) & $32 \pm 7$ & $26 \pm 9$ & 22 & $<.001$ \\
\hline MPAP/MAP ratio & $0.44 \pm 0.11$ & $0.34 \pm 0.15$ & 22 & .001 \\
\hline $\mathrm{Cl}\left(\mathrm{L} \cdot{ }^{-1} \cdot \mathrm{m}^{-2}\right)$ & $2.4 \pm 0.5$ & $2.6 \pm 0.6$ & 10 & .635 \\
\hline CVP $(\mathrm{mm} \mathrm{Hg})$ & $18 \pm 5$ & $15 \pm 6$ & 22 & .015 \\
\hline Wedge $(\mathrm{mm} \mathrm{Hg})$ & $20 \pm 4$ & $16 \pm 0$ & 2 & .41 \\
\hline PVR (dynes $\cdot \mathrm{s} \cdot \mathrm{cm}^{-5}$ ) & $212 \pm 78$ & $139 \pm 23$ & 2 & .307 \\
\hline SVR (dynes $\cdot \mathrm{s} \cdot \mathrm{cm}^{-5}$ ) & $1147 \pm 414$ & $1069 \pm 218$ & 7 & .708 \\
\hline
\end{tabular}

${ }_{i P G I_{2}}$, Inhaled prostacyclin; $M A P$, mean arterial blood pressure; $P A P$, pulmonary artery pressure; $M P A P$, mean pulmonary artery pressure; $C l$, cardiac index; $C V P$, central venous pressure; $P V R$, pulmonary vascular resistance; $S V R$, systemic vascular resistance.

TABLE 4. Hemodynamic parameters for patients with pulmonary hypertension: baseline and after the initiation of $\mathrm{PPGl}_{2}$

\begin{tabular}{|c|c|c|c|c|}
\hline Variable & Before $\mathrm{PGI}_{2}$ & After $\mathbf{P G I}_{2}$ & n & $P$ value \\
\hline $\mathrm{PaO}_{2} / \mathrm{F}_{10} \mathrm{O}_{2}$ ratio & $300 \pm 184$ & $319 \pm 168$ & 55 & .322 \\
\hline $\mathrm{MAP}(\mathrm{mm} \mathrm{Hg})$ & $76 \pm 12$ & $78 \pm 11$ & 109 & .148 \\
\hline PAP $(\mathrm{mm} \mathrm{Hg})$ & $36 \pm 9$ & $30 \pm 8$ & 107 & $<.001$ \\
\hline PAP/MAP ratio & $0.49 \pm 0.14$ & $0.40 \pm 0.12$ & 107 & $<.001$ \\
\hline $\mathrm{Cl}\left(\mathrm{L} \cdot \mathrm{min}^{-1} \cdot \mathrm{m}^{-2}\right)$ & $2.6 \pm 0.9$ & $2.8 \pm 0.9$ & 30 & .054 \\
\hline CVP (mm Hg) & $18 \pm 7$ & $18 \pm 8$ & 78 & .22 \\
\hline Wedge $(\mathrm{mm} \mathrm{Hg})$ & $18 \pm 2$ & $18 \pm 3$ & 11 & .933 \\
\hline PVR (dynes $\cdot \mathrm{s} \cdot \mathrm{cm}^{-5}$ ) & $358 \pm 164$ & $246 \pm 122$ & 11 & .005 \\
\hline SVR (dynes $\cdot \mathrm{s} \cdot \mathrm{cm}^{-5}$ ) & $1199 \pm 483$ & $1093 \pm 390$ & 19 & .291 \\
\hline
\end{tabular}

${ }_{i P G I}$, Inhaled prostacyclin; $M A P$, mean arterial blood pressure; $P A P$, pulmonary artery pressure; $C l$, cardiac index; $C V P$, central venous pressure; $P V R$, pulmonary vascular resistance; $S V R$, systemic vascular resistance.

activates platelet adenylate cyclase and augments cyclic adenosine monophosphate formation by way of specific membrane receptors. van Heerden and colleagues ${ }^{14}$ demonstrated that even though significant levels of 6-keto-prostaglandin $F_{1} \alpha$ could be demonstrated in patients receiving iPGI $_{2}$ for ARDS, there was no effect on platelet aggregation as measured by the response to adenosine diphosphate. In a double-blind, placebo-controlled randomized study over 4 to 6 hours of administration of iPGI 2 , Haraldsson and associates $^{27}$ reported that even though antiplatelet effects could be detected by in vitro measurements such as platelet aggregation and thromboelastography, these effects were not clinically detected as measured by chest tube output and bleeding times after on-pump cardiac surgery. On the basis of these findings, we therefore did not monitor blood levels of either $\mathrm{PGI}_{2}$ or its metabolite. Our results corroborate this because the re-exploration rate for bleeding was low. In contrast to the increasing bleeding times, there is also a theoretical concern that when platelets are exposed to extended periods of $\mathrm{PGI}_{2}$ or its chemical analogs it may result in a time- and dose-dependent desensitization of the prostacyclin receptor. ${ }^{28}$ Darius and associates ${ }^{28}$ showed that 
TABLE 5. Hemodynamic parameters for patients with pulmonary hypertension: baseline and after 4 to $6 \mathrm{~h}$ on $\mathrm{PPGI}_{2}$

\begin{tabular}{|c|c|c|c|c|}
\hline Variable & Before $\mathrm{PGI}_{2}$ & 4 to $6 \mathrm{~h}$ after & n & $P$ value \\
\hline $\mathrm{PaO}_{2} / \mathrm{FiO}_{2}$ ratio & $282 \pm 164$ & $302 \pm 166$ & 37 & .442 \\
\hline MAP $(\mathrm{mm} \mathrm{Hg})$ & $76 \pm 11$ & $78 \pm 11$ & 89 & .16 \\
\hline $\mathrm{PAP}(\mathrm{mm} \mathrm{Hg})$ & $36 \pm 9$ & $25 \pm 8$ & 86 & $<.001$ \\
\hline PAP/MAP ratio & $0.48 \pm 0.13$ & $0.33 \pm 0.13$ & 86 & $<.001$ \\
\hline $\mathrm{CI}\left(\mathrm{L} \cdot \mathrm{min}^{-1} \cdot \mathrm{m}^{-2}\right)$ & $2.6 \pm 0.8$ & $2.9 \pm 0.8$ & 33 & .042 \\
\hline CVP (mm Hg) & $19 \pm 7$ & $13 \pm 6$ & 67 & $<.001$ \\
\hline Wedge $(\mathrm{mm} \mathrm{Hg})$ & $17 \pm 4$ & $16 \pm 5$ & 6 & .615 \\
\hline PVR (dynes $\cdot \mathrm{s} \cdot \mathrm{cm}^{-5}$ ) & $212 \pm 40$ & $157 \pm 38$ & 5 & .078 \\
\hline SVR (dynes $\left.\cdot \mathrm{s} \cdot \mathrm{cm}^{-5}\right)$ & $1133 \pm 572$ & $931 \pm 249$ & 22 & .131 \\
\hline
\end{tabular}

$i_{i P G}$, Inhaled prostacyclin; $M A P$, mean arterial blood pressure; $P A P$, pulmonary artery pressure; $C l$, cardiac index; $C V P$, central venous pressure; $P V R$, pulmonary vascular resistance; SVR, systemic vascular resistance.

TABLE 6. Hemodynamic parameters for patients with right ventricular dysfunction: baseline and after the initiation of $\mathrm{iPGI}_{2}$

\begin{tabular}{|c|c|c|c|c|}
\hline Variable & Before $\mathrm{PPGI}_{2}$ & After iPGI $_{2}$ & $n$ & $P$ value \\
\hline $\mathrm{PaO}_{2} / \mathrm{FlO}_{2}$ ratio & $287 \pm 157$ & $357 \pm 134$ & 7 & .11 \\
\hline $\mathrm{MAP}(\mathrm{mm} \mathrm{Hg})$ & $78 \pm 11$ & $81 \pm 11$ & 16 & .356 \\
\hline PAP (mm Hg) & $34 \pm 10$ & $29 \pm 10$ & 15 & .007 \\
\hline MPAP/MAP ratio & $0.43 \pm 0.12$ & $0.35 \pm 0.11$ & 15 & .002 \\
\hline $\mathrm{Cl}\left(\mathrm{L} \cdot \mathrm{min}^{-1} \cdot \mathrm{m}^{-2}\right)$ & $1.9 \pm 0.3$ & $2.2 \pm 0.6$ & 12 & .036 \\
\hline $\operatorname{CVP}(\mathrm{mm} \mathrm{Hg})$ & $21 \pm 5$ & $19 \pm 6$ & 16 & .058 \\
\hline Wedge $(\mathrm{mm} \mathrm{Hg})$ & $18 \pm 2$ & $17 \pm 3$ & 6 & .135 \\
\hline PVR (dynes $\cdot \mathrm{s} \cdot \mathrm{cm}^{-5}$ ) & $321 \pm 130$ & $243 \pm 130$ & 6 & .05 \\
\hline SVR (dynes $\cdot \mathrm{s} \cdot \mathrm{cm}^{-5}$ ) & $1338 \pm 549$ & $1104 \pm 407$ & 10 & .014 \\
\hline
\end{tabular}

$i_{i P G}$, Inhaled prostacyclin; $M A P$, mean arterial blood pressure; $P A P$, pulmonary artery pressure; $M P A P$, mean pulmonary artery pressure; $C l$, cardiac index; $C V P$, central venous pressure; $P V R$, pulmonary vascular resistance; $S V R$, systemic vascular resistance.

TABLE 7. Hemodynamic parameters for patients with right ventricular dysfunction: baseline and after 4 to $6 \mathrm{~h}$ on $\mathrm{iPGI}_{2}$

\begin{tabular}{|c|c|c|c|c|}
\hline Variable & Before $\mathrm{PGI}_{2}$ & 4 to $6 \mathrm{~h}$ after & n & $P$ value \\
\hline $\mathrm{PaO}_{2} / \mathrm{FiO}_{2}$ ratio & $250 \pm 86$ & $284 \pm 105$ & 5 & .552 \\
\hline MAP $(\mathrm{mm} \mathrm{Hg})$ & $80 \pm 11$ & $72 \pm 7$ & 13 & .056 \\
\hline PAP $(\mathrm{mm} \mathrm{Hg})$ & $34 \pm 11$ & $24 \pm 9$ & 13 & .002 \\
\hline MPAP/MAP ratio & $0.42 \pm 0.12$ & $0.34 \pm 0.14$ & 13 & .032 \\
\hline $\mathrm{Cl}\left(\mathrm{L} \cdot \mathrm{min}^{-1} \cdot \mathrm{m}^{-2}\right)$ & $1.9 \pm 0.3$ & $2.6 \pm 0.6$ & 7 & .038 \\
\hline CVP $(\mathrm{mm} \mathrm{Hg})$ & $20 \pm 5$ & $14 \pm 6$ & 13 & .006 \\
\hline Wedge $(\mathrm{mm} \mathrm{Hg})$ & $17 \pm 1.4$ & $9.5 \pm 5$ & 2 & .205 \\
\hline PVR (dynes $\cdot \mathrm{s} \cdot \mathrm{cm}^{-5}$ ) & $202 \pm 18$ & $147 \pm 8$ & 2 & .212 \\
\hline SVR (dynes $\cdot \mathrm{s} \cdot \mathrm{cm}^{-5}$ ) & $1231 \pm 518$ & $999 \pm 281$ & 9 & .216 \\
\hline
\end{tabular}

$i P G I_{2}$, Inhaled prostacyclin; $M A P$, mean arterial blood pressure; $P A P$, pulmonary artery pressure; $M P A P$, mean pulmonary artery pressure; $C l$, cardiac index; $C V P$, central venous pressure; $P V R$, pulmonary vascular resistance; $S V R$, systemic vascular resistance.

there was an in vitro platelet $\mathrm{PGI}_{2}$ receptor desensitization that caused a marked augmentation of platelet/endothelial cell adhesion. This could theoretically cause thrombus formation. Our data and safety monitoring committee reviewed all adverse events and found no hematologic adverse events attributable to $\mathrm{iPGI}_{2}$.

Inhaled $\mathrm{PGI}_{2}$ is a potent vasodilator. ${ }^{5}$ However, as in other studies, we did not detect significant systemic hypotension. It has subsequently been confirmed that $\mathrm{PPGI}_{2}$ has no systemic hypotensive effects in doses up to $50 \mathrm{ng} \cdot \mathrm{kg}^{-1}$ $\cdot \min ^{-1}$, even though significant levels of its metabolite 6-keto-prostaglandin $\mathrm{F}_{1} \alpha$ were detected. ${ }^{14}$ At the dose ranges used in our study and in others, not enough $\mathrm{PGI}_{2}$ reaches the systemic circulation to cause significant vasodilation. To maintain ease of administration and considering the principles of inhalational drug delivery, we elected to use a concentration-based rather than a weight-based protocol. Even at the highest concentration $(20,000 \mathrm{ng} / \mathrm{mL})$, this amounted to an average of $37 \mathrm{ng} \cdot \mathrm{kg}^{-1} \cdot \mathrm{min}^{-1}$. On the basis of previously published dose-response studies, this dose is well below the recommended safe inhalational dose of $50 \mathrm{ng} \cdot \mathrm{kg}^{-1} \cdot \mathrm{min}^{-1} \cdot{ }^{14,29}$ The beneficial effects of the 
TABLE 8. Effect of inhaled prostacyclin ( $\mathrm{iPGI}_{2}$ ) on hemodynamic parameters: baseline and after the initiation of $\mathrm{iPGl}_{2}{ }^{*}$

\begin{tabular}{|c|c|c|c|c|}
\hline Variable & Before $\mathbf{P G I}_{2}$ & After $\mathbf{P G I}_{2}$ & n & $P$ value \\
\hline $\mathrm{PaO}_{2} / \mathrm{FlO}_{2}$ ratio & $260 \pm 186$ & $290 \pm 173$ & 68 & .075 \\
\hline $\mathrm{MAP}(\mathrm{mm} \mathrm{Hg})$ & $77 \pm 12$ & $78 \pm 11$ & 125 & .371 \\
\hline MPAP (mm Hg) & $35 \pm 9$ & $30 \pm 8$ & 116 & $<.001$ \\
\hline MPAP/MAP ratio & $0.47 \pm 0.14$ & $0.39 \pm 0.13$ & 116 & $<.001$ \\
\hline $\mathrm{CI}\left(\mathrm{L} \cdot \mathrm{min}^{-1} \cdot \mathrm{m}^{-2}\right)$ & $2.6 \pm 0.9$ & $2.7 \pm 0.9$ & 37 & .113 \\
\hline CVP $(\mathrm{mm} \mathrm{Hg})$ & $18 \pm 7$ & $17 \pm 8$ & 91 & .113 \\
\hline Wedge $(\mathrm{mm} \mathrm{Hg})$ & $18 \pm 2$ & $18 \pm 3$ & 13 & .802 \\
\hline PVR (dynes $\left.\cdot \mathrm{s} \cdot \mathrm{cm}^{-5}\right)$ & $335 \pm 160$ & $246 \pm 112$ & 13 & .015 \\
\hline SVR (dynes $\cdot \mathrm{s} \cdot \mathrm{cm}^{-5}$ ) & $1255 \pm 534$ & $1121 \pm 405$ & 24 & .116 \\
\hline $\mathrm{SvO}_{2}(\%)$ & $70 \pm 14$ & $72 \pm 10$ & 24 & .332 \\
\hline
\end{tabular}

$\mathrm{FIO}_{2}$, Fraction of inspired oxygen; $M A P$, mean arterial blood pressure; $M P A P$, mean pulmonary artery pressure; $\mathrm{Cl}$, cardiac index; $C V P$, central venous pressure; $P V R$, pulmonary vascular resistance; $S V R$, systemic vascular resistance; $S \mathrm{~V}_{2}$, mixed venous oxygen saturation.

${ }^{*}$ The small $n$ in the number of wedge pressures and cardiac output measurements (and hence derived parameters, such as PVR and SVR) reflects the inability to obtain these parameters for a variety of reasons, including tricuspid regurgitation (inaccurate, meaningless cardiac output) or the inability to wedge the catheter. See Discussion section.

TABLE 9. Effect of inhaled prostacyclin ( $\mathrm{iPGI}_{2}$ ) on hemodynamic parameters: baseline and after 4 to $6 \mathrm{~h}$ on $\mathrm{iPGI}_{2}{ }^{*}$

\begin{tabular}{|c|c|c|c|c|}
\hline Variable & Before $\mathrm{PGI}_{2}$ & 4 to $6 \mathrm{~h}$ after & $\mathbf{n}$ & $P$ value \\
\hline $\mathrm{PaO}_{2} / \mathrm{FlO}_{2}$ ratio & $256 \pm 167$ & $281 \pm 164$ & 43 & .269 \\
\hline MAP (mm Hg) & $76 \pm 11$ & $78 \pm 11$ & 98 & .253 \\
\hline MPAP (mm Hg) & $35 \pm 9$ & $24 \pm 8$ & 92 & $<.001$ \\
\hline MPAP/MAP ratio & $0.47 \pm 0.14$ & $0.32 \pm 0.12$ & 92 & $<.001$ \\
\hline Cardiac output (L/min) & $4.6 \pm 1.5$ & $5.3 \pm 1.6$ & 36 & .037 \\
\hline $\mathrm{Cl}\left(\mathrm{L} \cdot \min ^{-1} \cdot \mathrm{m}^{-2}\right)$ & $2.5 \pm 0.8$ & $2.9 \pm 0.8$ & 36 & .036 \\
\hline $\mathrm{CVP}(\mathrm{mm} \mathrm{Hg})$ & $18 \pm 6$ & $13 \pm 6$ & 73 & $<.001$ \\
\hline Wedge $(\mathrm{mm} \mathrm{Hg})$ & $17 \pm 4$ & $15 \pm 5$ & 7 & .424 \\
\hline PVR (dynes $\cdot \mathrm{s} \cdot \mathrm{cm}^{-5}$ ) & $209 \pm 37$ & $156 \pm 34$ & 6 & \\
\hline SVR (dynes $\cdot \mathrm{s} \cdot \mathrm{cm}^{-5}$ ) & $1143 \pm 553$ & $961 \pm 265$ & 24 & .137 \\
\hline $\mathrm{SvO}_{2}(\%)$ & $69 \pm 12$ & $69 \pm 11$ & 24 & .708 \\
\hline
\end{tabular}

$\mathrm{FIO}_{2}$, Fraction of inspired oxygen; MAP, mean arterial blood pressure; MPAP, mean pulmonary artery pressure; $\mathrm{Cl}$, cardiac index; $\mathrm{CVP}$, central venous pressure; $P V R$, pulmonary vascular resistance; $S V R$, systemic vascular resistance; $\mathrm{SVO}_{2}$, mixed venous oxygen saturation.

${ }^{*}$ The small $\mathrm{n}$ in the number of wedge pressures and cardiac output measurements (and hence derived parameters, such as PVR and SVR) reflects the inability to obtain these parameters for a variety of reasons, including tricuspid regurgitation (inaccurate, meaningless cardiac output) or the inability to wedge the catheter. See Discussion section.

drug were therefore observed even at these dosages that were lower than previously published.

Inhaled $\mathrm{PGI}_{2}$ has several advantages over iNO. It is easy to administer and requires no special monitoring equipment during administration. It can also safely be administered to extubated patients via a face mask. This route of administration was very well tolerated and did not cause any eye irritation or sore throat, unlike iNO, which can cause methemoglobinemia and buildup of oxygen free radicals and nitrogen dioxide. ${ }^{3}$ Inhaled $\mathrm{PGI}_{2}$ does not have toxic metabolites that require monitoring. It is stored in a crystallized powder form at room temperature, its final preparation with the special glycine diluent is fast and easy, and it is readily available.

There are certain precautions that have to be considered when administering $\mathrm{iPGI}_{2}$. The final preparation has to be shielded from light because of the potential for light degradation. Care has to be taken during transport to prevent accidental spilling of the drug down the inspiratory limb into the patient's trachea. Another disadvantage of $\mathrm{iPGI}_{2}$ is the inability to adequately deliver the nebulized drug to patients in whom large-volume pulmonary edema develops. As previously mentioned, the glycine buffer makes the aerosol "sticky." Filters on ventilators and BIPAP machines therefore need to be frequently changed to prevent the development of a stuck ventilator valve and auto-PEEP.

We have demonstrated that there are potentially large cost savings when $\mathrm{iPGI}_{2}$ is used instead of iNO. These cost savings would be even more substantial if the costs associated with monitoring for iNO toxicity were considered. The relatively low cost, together with the excellent safety profile, may allow for the use of $\mathrm{iPGI}_{2}$ in many patients in whom iNO might not have been considered because of the enormous costs currently associated with it. Inhaled NO should still be readily available in cases in which patients do not respond to $\mathrm{iPGI}_{2}$. Similarly, in patients with severe 
pulmonary hypertension or refractory hypoxemia, these 2 agents combined, may provide additive effects. ${ }^{30}$

There are several limitations to the study. There was no control group in our study, nor did we directly compare $\mathrm{iPGI}_{2}$ with iNO. We did not believe that a control or placebo group could be used in these critically ill patients, nor could we stop the agent to allow patients to serve as their own controls. However, this has previously been addressed in other studies, albeit in small numbers of patients. ${ }^{8,12,13,20-22}$ Another limitation is that there are many confounding variables that affect the hemodynamic parameters that we measured. We did not standardize the intraoperative and anesthetic management or the postoperative critical care, including vasoactive drug strategies and ventilation strategies. This would not have been possible, considering the heterogeneous group of patients. As a result, not all the changes observed in our study may be attributable to iPGI $_{2}$. It is likely that the immediate changes (before and after) are linked to $\mathrm{iPGI}_{2}$ but that some of the changes seen 4 to 6 hours after initiation of the drug were due to confounding variables and the natural history of the pathophysiological process. For example, a decrease in CVP may have been due to a decrease in volume status or an improvement in right ventricular function. Similarly, the decrease in MPAP may be due to an improvement in many of the factors that are known to affect pulmonary artery pressures, including oxygenation, $\mathrm{CO}_{2}$ levels, acid-base status, functional residual capacity, vasopressor use, and shivering. Another limitation is that we do not have complete data for some variables, such as pulmonary vascular resistance, wedge pressure, and CVP, at the 4- to 6-hour time point. This is due to a number of factors that commonly occur in these patients. First, some of the patients were already weaned from ${ } \mathrm{PGI}_{2}$ by the time of the 4- to 6-hour measurements. Second, it is a safe and common intensive care unit practice that the pulmonary artery catheter is not wedged in patients who have a high risk for potential pulmonary artery rupture, eg, patients with pulmonary hypertension. Third, many of the patients in this study are at risk for tricuspid regurgitation, such as those with pulmonary hypertension and right ventricular dysfunction. Thermodilution measurements of cardiac output are inaccurate in the presence of tricuspid regurgitation. Therefore, all those derived variables that rely on cardiac output, such as pulmonary vascular resistance, may be inaccurate. The only way to reliably measure flow in these circumstances is to use a technology that is independent of tricuspid regurgitation.

In summary, $\mathrm{iPGI}_{2}$ seems to be a safe, effective, and cost-effective selective pulmonary artery vasodilator in this large and diverse group of cardiothoracic surgery patients. Although the route of delivery has not yet been FDA approved, this feasibility study now adds to the preponderance of evidence that shows that the inhalational use of $\mathrm{PGI}_{2}$ is an acceptable alternative to iNO.

We like to thank the following for their contributions to our study: (1) members of the Division of Cardiothoracic Anesthesia (Stefani Bruemmer-Smith, MD; Seema P. Deshpande, MD; George Despotis, MD; Charles B. Hantler, MD; Charl W. Hogue, Jr, MD; Nand K. Kodwani, MD; Sarah McMurry, MD; and Maurizio Renna, MD) for initial drug preparation and setup in the operating room and for obtaining intraoperative hemodynamic data; (2) the Division of Cardiothoracic Surgery (Joel D. Cooper, MD; Ralph J. Damiano, Jr, MD; Richard J. Battafarano, MD; Jennifer S. Lawton, MD; Bryan F. Meyers, MD; Nader Moazami, MD; Marc R. Moon, MD; G. Alexander Patterson, MD; and Michael K. Pasque, MD) for allowing enrollment of their patients during surgery and after surgery in the intensive care unit and for providing editorial comments in preparation for the meeting abstract and initial study design; (3) the Department of Respiratory Therapy for changing ventilator filters and setting up the $\mathrm{PGI}_{2}$ in the intensive care unit; and (4) nurses in the intensive care unit for obtaining hemodynamic parameters and in helping with implementation of the study.

\section{References}

1. Rossaint R, Falke KJ, Lopez F, Slama K, Pison U, Zapol WM. Inhaled nitric oxide for the adult respiratory distress syndrome. $N$ Engl J Med. 1993;328:399-405.

2. Fiser SM, Cope JT, Kron IL, Kaza AK, Long SM, Kern JA, et al. Aerosolized prostacyclin (epoprostenol) as an alternative to inhaled nitric oxide for patients with reperfusion injury after lung transplantation. J Thorac Cardiovasc Surg. 2001;121:981-2.

3. Weinberger B, Laskin DL, Heck DE, Laskin JD. The toxicology of inhaled nitric oxide. Toxicol Sci. 2001;59:5-16.

4. Lowson SM. Inhaled alternatives to nitric oxide. Anesthesiology. 2002; 96:1504-13.

5. Kadowitz PJ, Chapnick BM, Feigen LP, Hyman AL, Nelson PK, Spannhake EW. Pulmonary and systemic vasodilator effects of the newly discovered prostaglandin, PGI2. J Appl Physiol. 1978;45:40813.

6. Rubin LJ, Mendoza J, Hood M, McGoon M, Barst R, Williams WB, et al. Treatment of primary pulmonary hypertension with continuous intravenous prostacyclin (epoprostenol). Results of a randomized trial. Ann Intern Med. 1990;112:485-91.

7. Welte M, Zwissler B, Habazettl H, Messmer K. PGI2 aerosol versus nitric oxide for selective pulmonary vasodilation in hypoxic pulmonary vasoconstriction. Eur Surg Res. 1993;25:329-40.

8. Haraldsson A, Kieler-Jensen N, Nathorst-Westfelt U, Bergh CH, Ricksten SE. Comparison of inhaled nitric oxide and inhaled aerosolized prostacyclin in the evaluation of heart transplant candidates with elevated pulmonary vascular resistance. Chest. 1998;114:780-6.

9. Haraldsson A, Kieler-Jensen N, Ricksten SE. Inhaled prostacyclin for treatment of pulmonary hypertension after cardiac surgery or heart transplantation: a pharmacodynamic study. J Cardiothorac Vasc Anesth. 1996;10:864-8.

10. Mikhail G, Gibbs J, Richardson M, Wright G, Khaghani A, Banner N, et al. An evaluation of nebulized prostacyclin in patients with primary and secondary pulmonary hypertension. Eur Heart J. 1997;18:1499504.

11. Max M, Kuhlen R, Dembinski R, Rossaint R. Effect of aerosolized prostacyclin and inhaled nitric oxide on experimental hypoxic pulmonary hypertension. Intensive Care Med. 1999;25:1147-54.

12. Walmrath D, Schneider T, Schermuly R, Olschewski H, Grimminger F, Seeger W. Direct comparison of inhaled nitric oxide and aerosolized prostacyclin in acute respiratory distress syndrome. Am J Respir Crit Care Med. 1996;153:991-6. 
13. Zwissler B, Kemming G, Habler O, Kleen M, Merkel M, Haller M, et al. Inhaled prostacyclin (PGI2) versus inhaled nitric oxide in adult respiratory distress syndrome. Am J Respir Crit Care Med. 1996;154: 1671-7.

14. van Heerden PV, Barden A, Michalopoulos N, Bulsara MK, Roberts BL. Dose-response to inhaled aerosolized prostacyclin for hypoxemia due to ARDS. Chest. 2000;117:819-27.

15. Walmrath D, Schneider T, Pilch J, Grimminger F, Seeger W. Aerosolised prostacyclin in adult respiratory distress syndrome. Lancet. 1993;342:961-2.

16. Olschewski H, Walmrath D, Schermuly R, Ghofrani A, Grimminger F, Seeger W. Aerosolized prostacyclin and iloprost in severe pulmonary hypertension. Ann Intern Med. 1996;124:820-4.

17. Schroeder RA, Wood GL, Plotkin JS, Kuo PC. Intraoperative use of inhaled PGI(2) for acute pulmonary hypertension and right ventricular failure. Anesth Analg. 2000;91:291-5.

18. Eichelbronner O, Reinelt H, Wiedeck H, Mezody M, Rossaint R, Georgieff M, et al. Aerosolized prostacyclin and inhaled nitric oxide in septic shock-different effects on splanchnic oxygenation? Intensive Care Med. 1996;22:880-7.

19. Rocca GD, Coccia C, Pompei L, Ruberto F, Venuta F, De Giacomo T, et al. Hemodynamic and oxygenation changes of combined therapy with inhaled nitric oxide and inhaled aerosolized prostacyclin. J Cardiothorac Vasc Anesth. 2001;15:224-7.

20. Putensen C, Hormann C, Kleinsasser A, Putensen-Himmer G. Cardiopulmonary effects of aerosolized prostaglandin E1 and nitric oxide inhalation in patients with acute respiratory distress syndrome. Am J Respir Crit Care Med. 1998;157:1743-7.

21. Zwissler B, Welte M, Messmer K. Effects of inhaled prostacyclin as compared with inhaled nitric oxide on right ventricular performance in hypoxic pulmonary vasoconstriction. J Cardiothorac Vasc Anesth. 1995;9:283-9.

22. Zwissler B, Welte M, Habler O, Kleen M, Messmer K. Effects of inhaled prostacyclin as compared with inhaled nitric oxide in a canine model of pulmonary microembolism and oleic acid edema. $J$ Cardiothorac Vasc Anesth. 1995;9:634-40.

23. Kukovetz WR, Holzmann S, Wurm A, Poch G. Prostacyclin increases cAMP in coronary arteries. J Cyclic Nucleotide Res. 1979;5:469-76.

24. Rao GH, Reddy KR, Hagert K, White JG. Influence of $\mathrm{pH}$ on the prostacyclin (PGI2) mediated inhibition of platelet function. Prostaglandins Med. 1980;4:263-73.

25. Rosenkranz B, Fischer C, Frolich JC. Prostacyclin metabolites in human plasma. Clin Pharmacol Ther. 1981;29:420-4.

26. van Heerden PV, Gibbs NM, Michalopoulos N. Effect of low concentrations of prostacyclin on platelet function in vitro. Anaesth Intensive Care. 1997;25:343-6.

27. Haraldsson A, Kieler-Jensen N, Wadenvik H, Ricksten SE. Inhaled prostacyclin and platelet function after cardiac surgery and cardiopulmonary bypass. Intensive Care Med. 2000;26:188-94.

28. Darius H, Binz C, Veit K, Fisch A, Meyer J. Platelet receptor desensitization induced by elevated prostacyclin levels causes platelet-endothelial cell adhesion. J Am Coll Cardiol. 1995;26:800-6.

29. Lowson SM, Doctor A, Walsh BK, Doorley PA. Inhaled prostacyclin for the treatment of pulmonary hypertension after cardiac surgery. Crit Care Med. 2002;30:2762-4.

30. Hill LL, Pearl RG. Combined inhaled nitric oxide and inhaled prostacyclin during experimental chronic pulmonary hypertension. $J$ Appl Physiol. 1999;86:1160-4.

\section{Discussion}

Dr David Fullerton (Chicago, Ill). You have a very large group of patients here. It is not common that one sees a surgical study of any kind with this number of patients, and as your data highlight, it is not rare to find pulmonary hypertension either with or without hypoxemia in a very broad spectrum of both cardiac and thoracic surgical patients. When it is severe, as in your study, it can be a very, very difficult problem to treat, and for that reason it is very important that we continue to pursue pharmacologic strategies to help us treat these people.
I think that what you have described for us is your clinical experience with this agent in treating a very complicated group of patients, so it is perfectly appropriate and it is perfectly understandable that you do have a heterogeneous group of patients. It is for that reason that you also have the inability in this sort of a project to control many of the other variables that may impact PAP, such as acid-base status, ventilator management, depth of anesthesia, and the administration of other vasoactive drugs.

Despite those limitations, I am intrigued that the agent works. I am also very impressed that it seems easy to administer. It seems very safe to administer, and it is certainly inexpensive. As you begin to refine your knowledge of this, there are a couple of questions that I do have for you.

Obviously we need a selective pulmonary vasodilator, and your data suggest-acknowledging the difficulty in acquiring full data sets with studies of this nature, your data nonetheless suggest that the agent selectively vasorelaxes the pulmonary circulation, but 1 question is - these patients were also receiving a variety of other vasoactive drugs given their critical illness. Do you have any experience in administering inhaled prostacyclin in the absence of any other vasoconstrictors that would be a little more conclusive in its pulmonary vasoselectivity?

Dr Moazami. Since, as you mentioned, Dr Fullerton, this was a clinical study, it is very difficult to tease out how inhaled prostacyclin may have affected the pulmonary pressures given that other agents, including milrinone and other vasodilators, were also being used concomitantly. In many cases the inhaled prostacyclin was started in the operating room after all those maneuvers had been done, and we did not see a clinical response. However, I do not have the data available on that, but interestingly, about 3 months ago there was an article from the Montreal Heart Institute where they looked at exactly what you suggested. They had 20 patients and they randomized them to either prostacyclin or placebo, and during surgery they made all these measurements before induction of anesthesia and after induction of anesthesia, and then they administered prostacyclin before the patients went on cardiopulmonary bypass, made those measurements, and then made their calculations. In fact, that study also conclusively shows that the MPAP decreases without any other agent being on board. Now that is a very different population of patients from those that we treated (after cardiopulmonary bypass).

Dr Fullerton. My second question is as follows. One way to address these problems in these kinds of studies is to permit each patient to serve as his or her own control and collect hemodynamic data, start the drug, reach a steady state, see if there has been any sort of benefit from the drug, and then stop the drug temporarily. This has a very short half-life. And see if the hemodynamic condition returns to baseline or exactly what happens and then rechallenge the patient with the drug in order to see if the salutary benefits are attributable to the drug, or there are so many other variables changing that perhaps 1 of them actually accounted for the hemodynamic data. Do you have any experience with that?

Dr Moazami. We do have experience with it. Actually, since we have had such a positive experience with inhaled prostacyclin, we now use it as our first agent of choice for the treatment of that condition. I think the condition that you are referring to is probably going to be best studied in the postoperative patient in whom we have to start this agent and everything else has been stabilized. 
Unfortunately, since in a lot of these patients the agent had been started during surgery, it is incredibly difficult to sort out those factors. We certainly have the data available, and maybe it would be interesting to get the patients who were just started after surgery where everything else had already been in place and we just started inhaled prostacyclin and see what the effect is. We certainly have not done it where we would start and then stop and then start again or cross over to nitric oxide, but certainly those are important questions that we can address. As mentioned, we have seen such a clinical benefit from it that now we use it routinely, and although this report is on 126 patients, we now have experience of more than 150 patients in whom we have used it.

Dr Fullerton. Congratulations.

Dr. Moazami. Thank you.

Access to The Journal of Thoracic and Cardiovascular Surgery Online is reserved for print subscribers!

Full-text access to The Journal of Thoracic and Cardiovascular Surgery Online is available for all print subscribers. To activate your individual online subscription, please visit The Journal of Thoracic and Cardiovascular Surgery Online, point your browser to http://www.mosby.com/jtcvs, follow the prompts to activate your online access, and follow the instructions. To activate your account, you will need your subscriber account number, which you can find on your mailing label (note: the number of digits in your subscriber account number varies from 6 to 10). See the example below in which the subscriber account number has been circled:

\section{Sample mailing label}

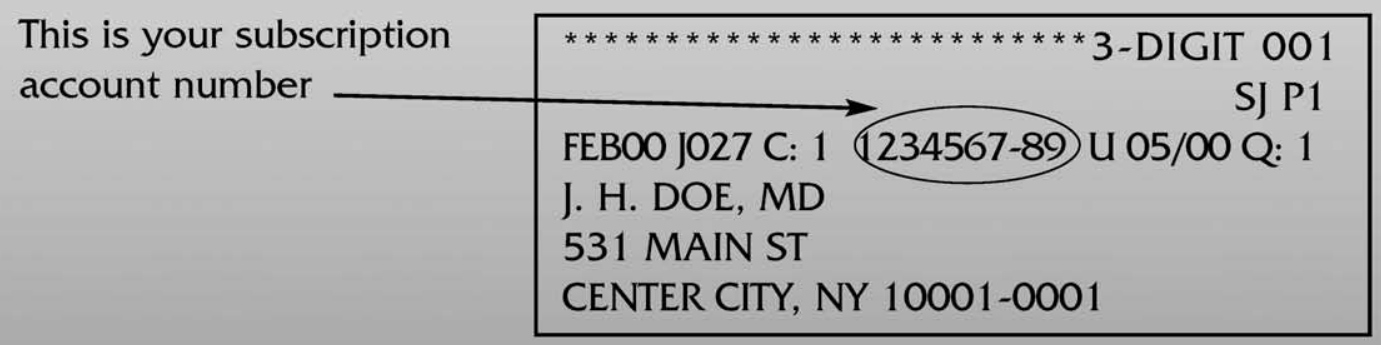

Personal subscriptions to The Journal of Thoracic and Cardiovascular Surgery Online are for individual use only and may not be transferred. Use of The Journal of Thoracic and Cardiovascular Surgery Online is subject to agreement to the terms and conditions as indicated online. 